\title{
Son iki dekatta endoskopi merkezinde özofajit görülme sıklığında saptanan değişiklik
}

\author{
The change in esophagitis detection rates during the last two decades at an endoscopy center
}

Mustafa SARIOĞLU, Gökhan KABAÇAM, Mehmet BEKTAŞ, Yusuf ÜSTÜN, Gülseren SEVEN, Mustafa YAKUT, Arzu YUSIFOVA, Fatih KARATAŞ, Esra YURDUSEVEN, Meryem EĞILMEZ, Deniz KIZILIRMAK, Uğur AYDOĞAN, Kubilay ÇINAR, Ramazan IDILMAN, Murat TÖRÜNER, Ali TÜZÜN, Irfan SOYKAN, Hakan BOZKAYA, Murat PALABIYIKOĞLU, Hasan ÖZKAN, Hülya ÇETINKAYA, Ali Reşit BEYLER, Kadir BAHAR, Selim KARAYALÇIN, Cihan YURDAYDIN, Necati ÖRMECI, Abdülkadir DÖKMECI, Ali ÖZDEN

Ankara Üniversitesi Tip Fakültesi Gastroenteroloji Bilim Dalı, Ankara

Giriş ve Amaç: Gastroözofageal reflü özofagusun en sık görülen hastalığıdır. Çalışmanın amacı yıllar içinde özofajit sıklı̆̆ında değişiklik olup olmadığını değerlendirmektir. Gereç ve Yöntem: Ankara Unniversitesi Gastroenteroloji Bilim Dalı Ibni Sina Hastanesi ve Cebeci Kliniği Endoskopi Merkezinde 19902008 yıllarında yapılan 63854 üst gastrointestinal sistem endoskopisi sonucu retrospektif olarak değerlendirildi. Özofajit derecelendirmesi Savary-Miller ve 1999'dan itibaren Los Angeles klasifikasyonuna göre yapılmıştı. Hastaların yaşları, cinsiyeti ve özofajite yandas endoskopik bulguları (hiatus hernisi, duodenal ülser, bulbus deformitesi, gastrik ülser, pilor stenozu, apikal darlık, mide operasyonu, gastrit, safra gastriti) kaydedildi. Bulgular: Endoskopisi yapılan 63854 vakanın \%52.9'u kadındı. Yaş ortalaması 46.75 (15-98) idi. Hastalarin 10275 (\%16.1)'inde özofajit saptand. Bunlarin \%61.9'unda Grade I, \%26.5'inde Grade II, \%8. I'inde Grade III ve \%3.4'ünde Grade IV özofajit vardı. Hastaların yaşı arttıkça özofajit sıklığı ve şiddeti artmaktaydı $(<20$ yaș: \%14.6, $21-30$ yaș: \%17.5, 31-40 yaș: \%19, $41-50$ yaș: $\% 19.7,51-60$ yaș: $\% 19,61-70$ yaş: \%18.6, 71-80 yaş: \%21.4) ( $p=0.0001)$. Erkeklerde daha fazla özofajit saptand (\%22.3 vs \%16.1) ve bunlar daha ileri evreydi ( $p=0.0001$ ). Özofajit görülme sıklı̆̆ında 1990'dan günümüze 5'er yılık değerlendirmede lineer bir artıs saptandı (1990-1994: \%11.2; 1995-1999: \%12.7; 2000-2004: \%19.9; 2005-2008: \%20.9) (p=0.0001). Çok değişkenli analizde özofajit gelişmesiyle yaş, erkek cinsiyet, duodenal ülser hastalığı, pilor darhı̆̆ , hiatus hernisi, alt özofagus sfinkter gevşekliği, antral gastrit ve pangastrit ilişkili bulundu. Sonuç: Yaklaşık 20 yıllık değerlendirmede endoskopik incelemeler sırasında özofajit tespit edilme sıklığ1 \%16.1 bulunmuştur. 1990'lı yıllara göre 2000'li yıllarda özofajit görülme oranında artış mevcuttur. Olguların \%88.4'ünde hafif derecede (Grade I+II) özofajit vardı. Hiatus herni, alt özofagus sfinkter gevşekliği, pilor stenozu ve peptik ülser gibi durumlarda özofajit görülme riski daha yüksekti.

Anahtar Kelimeler: Özofajit, reflü, endoskopi, yıllara göre değişim

\section{GİISS}

Mide içeriğinin özofagusa geçmesi fizyolojik bir olaydır. Özofagusa geçen mide içeriğinin rahatsızlık yaratması veya özofagus hasarına neden olmasına Gastroözofageal Reflü Hastalığı (GÖRH) denir. Gelişimindeki en önemli unsur reflü önleyici mekanizmaların bozulmuş olmasıdır.

Gastroözofageal Reflü Hastalığı toplumda sık görülen, hayat kalitesini olumsuz etkileyen ve sağlık sistemine giderek daha
Background and Aims: Gastroesophageal reflux is the most frequent disease affecting the esophagus. The purpose of this study was to determine if there has been any change in esophagitis detection rates in recent years. Materials and Methods: All 63,854 upper gastrointestinal endoscopies performed at Ankara University, Gastroenterology Department, Ibn-i Sina and Cebeci Endoscopy Centers, between 1990 - 2008 were analyzed retrospectively. Grading for esophagitis was done using Savary - Miller Classification until 1999, after which the Los Angeles Classification was used. Age, sex, and other endoscopic findings like hiatal hernia, duodenal ulcer, bulbar deformity, gastric ulcer, pyloric stenosis, apical stenosis, gastric operations, gastritis, and alkaline reflux were recorded. Results: Of these 63,854 cases, 52.9\% were women. The mean age was 46.75 (15-98). Esophagitis was detected in 10,275 (16.1\%) cases. Severity was grade I in $61.9 \%$, II in $26.5 \%$, III in $8.1 \%$, and IV in $3.4 \%$. Esophagitis frequency and severity increased with age ( $<20$ years: $14.6 \%, 21$ 30 years: $17.5 \%, 31-40$ years: $19 \%, 41-50$ years: $19.7 \%, 51-60$ years: $19 \%$, $61-70$ years: $18.6 \%, 71-80$ years: $21.4 \%)(p=0.0001)$. Male patients had higher esophagitis incidence $(22.3 \%$ vs $16.1 \%)$ and severity $(p=0.0001)$. From 1990 to date, when analyzed in 5-year intervals, esophagitis frequency was found to increase linearly (1990-1994: 11.2\%; 1995-1999: 12.7\%; 2000-2004. 19.9\%; 2005-2008: 20.9\%) ( $p=0.0001)$. As a result of multivariate analysis, age, male sex, duodenal ulcer, pyloric stenosis, hiatal hernia, lower esophageal sphincter hypotonicity, antral gastritis, and pangastritis were related to esophagitis development. Conclusions: The esophagitis detection rate in endoscopies performed in the past 20 years was $16.1 \%$. There was an increase in esophagitis in the last decade compared to the prior decade. Mild (Grade I - II) esophagitis was detected in $88.4 \%$ of cases. Risk increased with compounding conditions like hiatal hernia, lower esophageal sphincter hypotonicity, pyloric stenosis, and peptic ulcer.

Key words: Esophagitis, reflux, endoscopy, annual change

fazla yük olan pahalı bir hastalıktır $(1,2)$. Hastalığın seyrinde, Barret özofagusu, hemoraji, striktür, perforasyon ve kanser gelişimi gibi ciddi komplikasyonlar geliştiği bilinmektedir.

Yetişkinlerin \%15-44'ünde ayda bir, \%20'sinde haftada bir, \%7'sinde günde bir kez reflü semptomları görüldüğü bildirilmiştir. Batı toplumunda üst sindirim sistemi endoskopisi yapilan hastaların \%15-25'inde özofajit bulunduğu raporlan- 
mıştır. Asya'dan yapılan çalışmalarda ise bu sıklığın \%0.816.3 gibi çok daha az sıklıkta görüldüğü bildirilmekte ve batılılaşmayla beraber sıklığın giderek arttığı iddia edilmektedir (3). Son yıllarda hem hekim ve hastaların farkındalığının artması ile daha fazla tanı konması, hem de prevalansında gerçek bir artış olduğu bildirilmektedir. Gastroenterolojistlerin \%90'ı ve aile hekimlerinin \%67'sinin görüşünün prevalansın arttığı yönünde olduğu bildirilmiştir (4). Bu çalışmanın amacı ülkemizde yıllar içinde özofajit sıklığında değişiklik olup olmadığını değerlendirmektir.

\section{GEREC VE YÖNTEM}

Ankara Üniversitesi Gastroenteroloji Bilim Dalı Ibni Sina Hastanesi ve Cebeci Kliniği Endoskopi merkezlerinde 1990 2008 yıllarında yapılan 63854 üst gastrointestinal sistem endoskopisi sonucu retrospektif olarak değerlendirildi. Çalışmaya alınan vakalar, işlem endikasyonu ve tekrar endoskopi olup olmaması gözetilmeden alındı. Özofajit derecelendirmesi 1999'a kadar Savary-Miller ve 1999 dan itibaren Los Angeles sınıflamalarına göre yapılmıştı (Tablo 1).

Hastaların yaşları, cinsiyeti ve özofajite yandaş endoskopik bulguları (hiatus hernisi, duodenal ülser, bulbus deformitesi, gastrik ülser, pilor stenozu, apikal darlık, mide operasyonu, gastrit, safra gastriti, özofagus ve mide kanseri) kaydedildi.

Istatistik analizler için SPSS 13.0 paket programı kullanıldı. Anlamlılık değeri p<0.05 olarak alındı. Çok değişkenli analizde Odd's oranları hesaplandı.

\section{BULGULAR}

Endoskopisi yapılan 63854 vakanın 33779 (\%52.9)'u kadın, 30075 (\%47.1)'i erkekti. Yaş ortalaması 46.75 (15-98) idi. Yapılan işlemlerin yıllara göre dağılımına bakıldığında tüm işlemlerin \%23.5'i 90-94; \%26.9'u 95-99; \%27.3'ü 00-04; \%22.2'si 05-08 arasında yapılmıştı.

Hastaların 10275 (\% 16.1)'inde özofajit saptandı. Bunların evrelere göre dağılımına göre \%61.9 ile en fazla Grade I özofajit görüldü (Şekil 1).

Hastaların yaşı arttıkça özofajit sıklığı ve şiddeti artmaktaydı (Şekil 2) $(\mathrm{p}=0.0001)$.
Erkeklerde daha fazla özofajit saptandı (\%22.3 vs \%16.1) ve bunlar daha ileri evreydi ( $\mathrm{p}=0.0001)$. Özofajit görülme sıkl1ğında 1990'dan günümüze 5'er yllık değerlendirmede lineer bir artış saptandı (Şekil 3) (p=0.0001).

Özofajite en sık eşlik eden bulgular Tablo 2'de görülmektedir. Endoskopide saptanan çeşitli üst gastrointestinal sistem (GIS) lezyonlarının varlığında, özofajit sıklığının değerlendirilme-
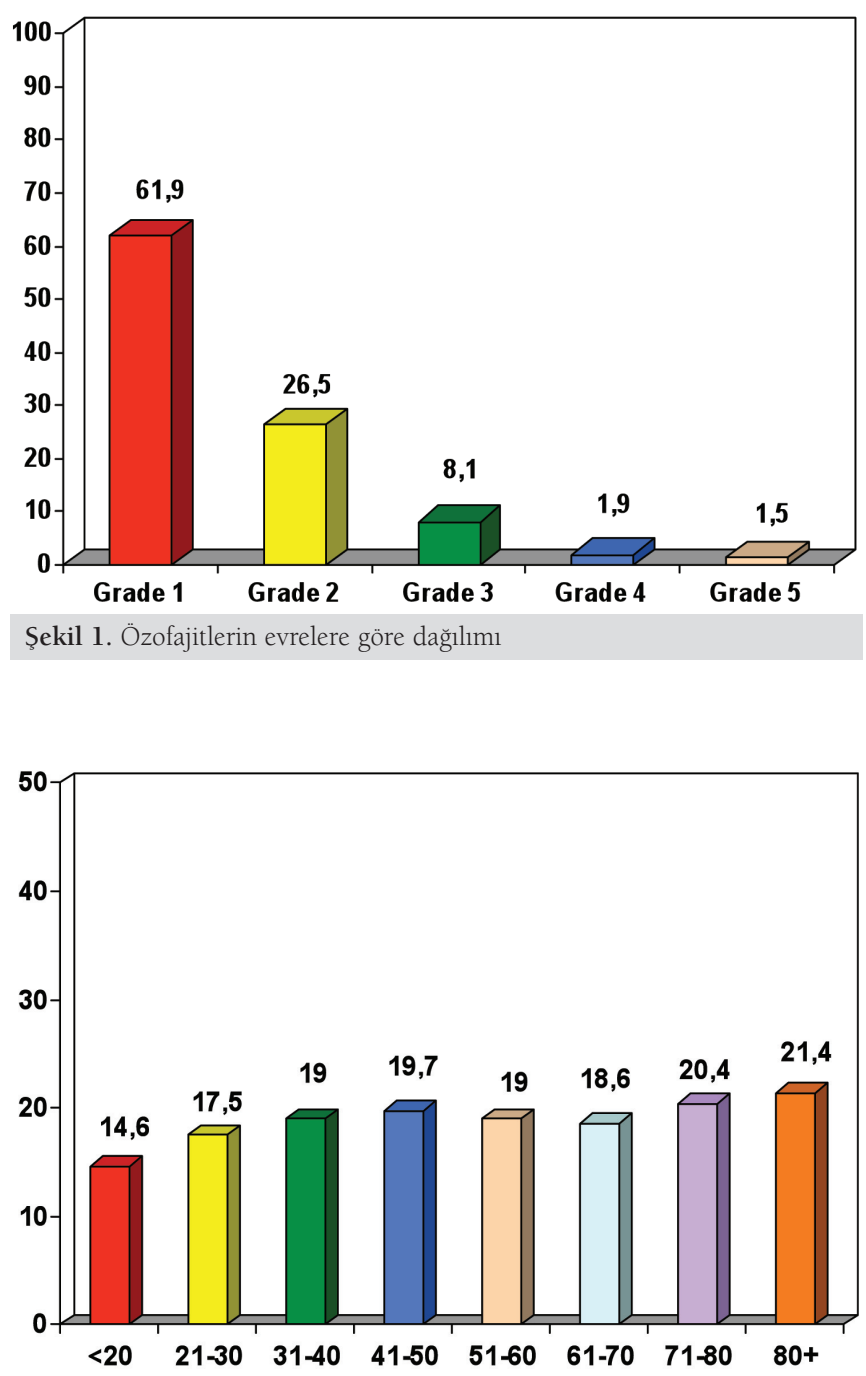

Şekil 2. Yaşla özofajit ilişkisi $(\mathrm{p}=0.0001)$

\begin{tabular}{|c|c|c|}
\hline Evre & Savary - Miller & Los Angeles \\
\hline I & $\begin{array}{l}\text { Bir alanda tek ya da birden fazla erozyonlar: Erozyonlar eritematöz ya } \\
\text { da eritematoeksudatif olabilir. }\end{array}$ & Mukozal katlantılar üzerinde bir veya daha fazla $\leq 5 \mathrm{~mm}$ erozyon \\
\hline II & $\begin{array}{l}\text { Birkaç alanda birden fazla erozyonlar: Erozyonlar birleşme eğilimin- } \\
\text { de olabilir. }\end{array}$ & Mukozal katlantılar üzerinde bir veya daha fazla $\geq 5 \mathrm{~mm}$ erozyon \\
\hline III & Birden fazla dairesel erozyonlar & $\begin{array}{l}\text { Iki veya daha fazla erozyonlar arasında çevrenin \% } 75 \text { 'ini geçmeyen } \\
\text { birleşmeler }\end{array}$ \\
\hline IV & Ülser, stenoz, ya da kısa özofagus (Braki-özofagus) & Çepeçevre özofagus alt ucu saran erozyonlar \\
\hline $\mathrm{V}$ & Barret özofagusu & - \\
\hline
\end{tabular}


sinde en sık hiatus hernisi, alt özofagus sfinkter (LES) gevşekliği ve pilor stenozunun varlığında özofajit görüldüğü saptandı (Şekil 4).

\begin{tabular}{lcc} 
Tablo 2. Özofajite en sik eşlik eden bulgular \\
Patoloji & N & $\%$ \\
Duodenal ülser & 10584 & 16,6 \\
LES* gevşekliği & 8585 & 13,4 \\
Hiatal herni & 5516 & 8,6 \\
Safra gastriti & 3418 & 5,4 \\
Opere mide & 1857 & 2,9 \\
Pilor stenozu & 443 & 0,7 \\
\hline *Es. Alt özofagus sfinkteri & &
\end{tabular}

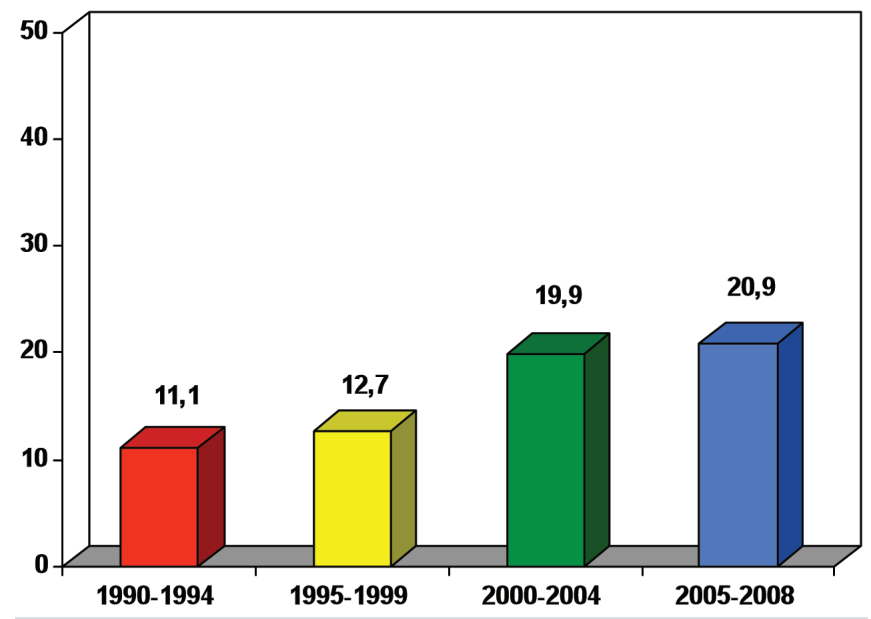

Şekil 3. Ylllara göre özofajit sıklığındaki değişim $(\mathrm{p}=0.0001)$

Eşlik eden bulguların özofajit gelişimine etkileri incelendiğinde, LES gevşekliği, hiatal herni, pilor stenozu, safra gastriti ve duodenal ülser varlığı istatistiksel yönden anlamlı bulundu ( $p<0.001)$. Mide ve özofagus kanseri, mide operasyonu öyküsü ve mide ülseri varlığında özofajit gelişimi genel popülasyondan farksızdı ( $p>0.05)$. Özofajit gelişmesine etkisi olan faktörlerin çok değişkenli analizi sonucunda, en önemli risk faktörlerinin hiatus hernisi (4.8 kat), LES gevşekliği (3.9 kat) ve pilor stenozu (2.5 kat) olduğu saptandı. Yaş, erkek cinsiyet, duodenal ülser hastalığı ve safra gastriti de bu riski artırıyordu (Tablo 3).

\section{TARTIŞMA}

Yapılan çalışmalarda, A.B.D.'de toplum genelinde eroziv özofajit sıklığının \%7, Avrupa'da \%2-10 arasında değiştiği bildirilmektedir (5). Son iki dekatta bu sıklık giderek artmaktadır (6). Örneğin semptomatik hastalarda \%30-70 oranında endoskopik olarak özofajit saptanmaktadır (7). Özofajit ve kronik iritasyonun neden olduğu Barret Özofagus zemininde gelişen adenokanser sıklığında da paralel bir artış vardır (8).

Ülkemizde yapılan bir çalışmada reflü tanımlayan olgularda

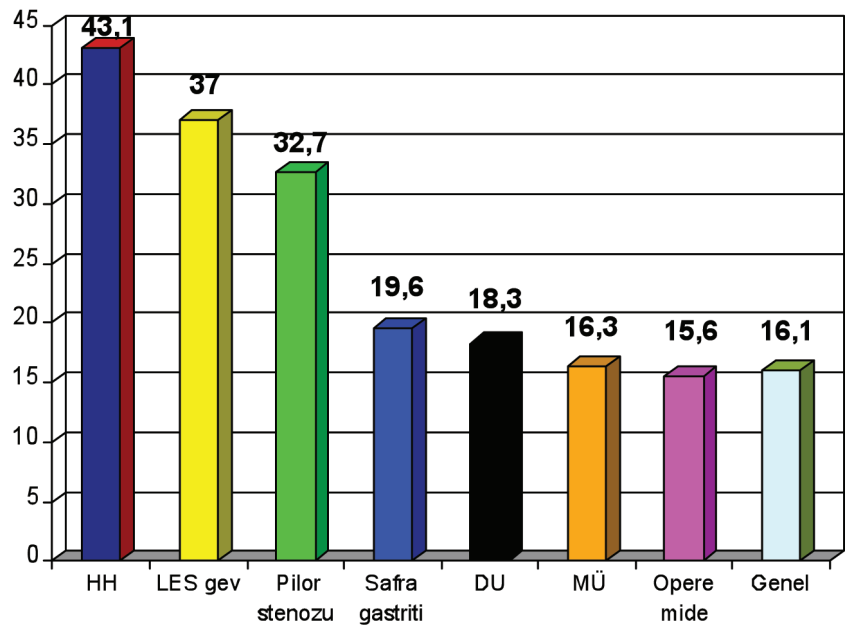

Şekil 4. Üst GIS lezyonları varlığında özofajit sıklığı

*HH: Hiatus hernisi, LES gev: Alt özofagus sfinkter gevşekliği, DU: Duodenal ülser, MÜ: Mide ülseri, Genel: Tüm popülasyon

endoskopi ile \%56 oranında değişik derecelerde reflü özofajit saptanmıştır (9). Bir başka çalışmada ise 5 yıllık bir sürede endoskopi merkezine dispeptik semptomlarla başvuran 9421 olgunun \%16'sında özofajit bulunmuştur. Bor ve arkadaşlarının, 21 ildeki 29 merkezin katılımıyla yaptığı ve haftada 1 veya daha çok reflü semptomu olan 1790 hastada yürütülen çalışmada özofajit sıklığı \%34 bulunmuştur (10).

Bizim çalışmamızda yaklaşık 20 yıllık değerlendirmede endoskopik incelemeler sırasında özofajit tespit edilme sıklığı \% 16.1 bulunmuştur. Alınan hasta grubunun heterojen olması, endikasyondan bağımsız olarak tüm işlemlerin alınması bu sonucu etkilemiş olabilir. Yine de saptanan oran literatürle uyumludur. Çalışmamızda yalnız endoskopik tanı alan vakalar olduğu için non-eroziv reflüsü olan, endoskopisi normal hastaların eklenmesiyle bu oranın daha da artabileceği düşünülmüştür.

Görüldüğü gibi 2000'li ylllarda özofajit görülme oranında belirgin artış mevcuttur. Bu oran 1990-1994 arası \%11 iken, 2004-2008 arası yaklaşık iki katına ulaşmıştır (\%20.9). Bir literatür taramasında reflü semptomlarının kıtalara göre yıllık değişimine bakıldığında Amerika'dan yapılan yayınlarda ortalama yıllık \%5'lik, Avrupa'da ise \%23.6 semptom artışı bulunmuştur (11). Benzer şekilde Singapur'dan yapılan bir ça-

$\begin{array}{lccc}\text { Tablo 3. Özofajit gelişimi için risk faktörleri } & \\ & \text { OR } & \text { CI \%95 } & \text { p } \\ \text { Cinsiyet } & 1.500 & 1.436-1.567 & <0.001 \\ \text { Yaş } & 1.003 & 1.002-1.004 & <0.001 \\ \text { Hiatal herni } & 4.845 & 4.570-5.136 & <0.001 \\ \text { LES gevşekliği } & 3.987 & 3.791-4.193 & <0.001 \\ \text { Pilor stenozu } & 2.559 & 2.096-3.125 & <0.001 \\ \text { Safra gastriti } & 1.288 & 1.180-1.405 & <0.001 \\ \text { Duodenal ülser } & 1.205 & 1.141-1.273 & <0.001\end{array}$


lışmada GÖRH sıklığının 1994'te \% 1.6'dan 2001'de \%10.6'ya çıktığı ancak bu artışın beden kitle indeksi, sigara veya alkol tüketimi ile ilişkisi olmadığı bildirilmiştir (12, 13). Malezya'da yapılan başka bir çalışmada da özofajit sıklığının 19912001 arasında \%2.7'den \%9'a çıktığı bildirilmiştir (14). Bunda sosyoekonomik koşulların iyileşmesi sonucu toplumun beslenme ve yaşam tarzındaki değişiklikler, obezitenin giderek artması da etkili görülmektedir. Ayrıca, tanı yöntemlerinin yaygınlaşması, sağlık hizmetlerine ulaşımın artması gibi faktörler, yalnız ülkemizde değil aynı zamanda gelişmekte olan diğer ülkelerde de hastalık prevalansının artmasına neden olmaktadır. Hatta gelişmişlik düzeyi düşük ve yüksek olan ülkeler arasında bu artışın oluşma zamanı arasında bir farktan söz edilmektedir. Buna göre gelişmiş ülkeler bu artışı yıllarca önce yaşamışlardır (6).

Hastalardaki özofajit evreleri; \%61.9 A, \%26.5 B, \%8.1 C, \%3.4 D olarak bulunmuştur. Olguların \%88.4'ünde hafif derecede (Grade I+II) özofajit vardır. Evreleme sistemi olarak 1999'a kadar Savary-Miller, bu yıldan sonra da Los Angeles sistemleri kullanılmıştır. Bu durum değerlendirmede minör farklara neden olmuş olabilir. Bunun nedeni, adı geçen ilk sıniflamanın 5'e, 2.'sinin ise 4'e ayrılmasındandır. Bor ve arkadaşlarının yaptığı çalışmada özofajit evresi bu sonuçlarla paralel şekilde, olguların \%62'sinde A, \%31 B, \%4 C, \%1 D olarak bulunmuştur. Bu çalışmada $H$. pylori sıklığ $\% 44$, hiatus hernisi ise \%19 oranında saptanmıs, Barret özofagusu ise \%4 oranında görülmüştür (10).

Yaşla birlikte daha ciddi vakalar artmaktadır. Çok değişkenli analizde hiatus hernisi, LES gevşekliği ve pilor stenozu özofajit riskini 4.8, 3.9 ve 2.5 kat artırıyor bulunmuştur. Mide içeriğinin distale taşınmasını bozan bu durumlarda prevalansın artması beklenen bir durumdur. Bunun dışında yaş, erkek cinsiyet, safra gastriti ve peptik ülser gibi durumlarda da özofajit görülme riski daha yüksek bulunmuştur. Son ylllarda duodenal ülserle ilişkisi bilinen $H$. pylori prevalansının artan sanitasyon ve eradikasyon tedavileri sonucunda azaldığı bildirilmektedir. Literatürde duodenal ülserli vakalarda özofajitin daha az görüldüğü ve eradikasyon sonrası arttığı yönünde bazı gözlemler yapılmış olsa da bizimki gibi bazı başka çalışmalarda bu sonuç desteklenmemiştir (15). Hastalıklı mukozanın iyileşmesi sonucunda asit salınımının düzelmesi mekanizması ile açıklanan bu durumla ilgili çalışmalar devam etmektedir (16).

Özofajit sıklığındaki artışın getirdiği sonuç, komplikasyonlarının artmasıdır. Örneğin, ABD'de 1975-2001 arasında özofagus Ca insidansında 6 kat artış tespit edilmiştir (17). Baret özofagus ve striktür sıklığında da benzer artışlar bulunmuştur (18-20). Bizim çalışmamızda, kanser gelişimi ile ilişki bulunmamıştır.

Çalışmanın en önemli kısıtlaması, endoskopi defterlerinden alınan kayıtların klinik ve patolojik veriler olmaksızın değerlendirilmesidir. Ancak bu denli geniş bir seride elde edilen sonuçlar bizce toplumumuzdaki trendler açısından çok önemlidir.

\section{SONUC}

Yaklaşık 20 ylllık değerlendirmede endoskopik incelemeler sırasında özofajit tespit edilme sıklığ \%16.1 bulunmuştur. 1990 'l yıllara göre 2000 li yıllarda özofajit görülme oranında 2 kata yakın artış mevcuttur. Olguların \%88.4'ünde hafif derecede (Grade I+II) özofajit vardı. Hiatus herni, LES gevşekliği, pilor stenozu ve peptik ülser gibi durumlarda özofajit görülme riski daha yüksek bulunmuştur.

\section{KAYNAKLAR}

1. Locke GR III, Talley NJ, Fett SL, et al. Prevalence and clinical spectrum of gastroesophageal reflux: A population-based study in Olmsted county, Minnesota. Gastroenterology 1997;112:1448-56.

2. Revicki DA, Wood M, Maton PN, Sorensen S. The impact of gastroesophageal reflux disease on quality of life. Am J Med 1998;104:252-8.

3. KL GOH. Changing epidemiology of gastroesophageal reflux disease in the Asian-Pacific region: An overview J Gastroenterol Hepatol 2004;19: 22-25.

4. Wong WM, Lim P, Wong BC. Clinical practice pattern of gastroenterologists, primary care physicians, and otolaryngologists for the management of GERD in the Asia-Pacific region: the FAST survey. J Gastroenterol Hepatol 2004;19:54-60.

5. Spechler SJ. Epidemiology and natural history of gastro-oesophageal reflux disease. Digestion 1992;51(Suppl 1):24-9.

6. El-Serag HB, Sonnenberg A. Opposing time trends of peptic ulcer and reflux disease. Gut 1998; 43: 327-33.

7. DeMeester TR, Wang CI, Wernly JA, et al. Technique, indications, and clinical use of 24 hour esophageal pH monitoring. Thorac Cardiovasc Surg 1980;79:656-70.
8. Brown LM, Devesa SS. Epidemiologic trends in esophageal and gastric cancer in the United States. Surg Oncol Clin N Am 2002;11:235-56.

9. Mungan Z, Demir K, Onuk M. D, Göral V, Boztaş G, Beşışık F, Yıldırım B, Yeğinsu O. Characteristics of gastroesophageal reflux disease in our country. Turk J Gastroenterol 1999;10:101-6.

10. Bor S, Vardar R, Vardar E, Takmaz S, Mungan Z, GÖRHEN çalışma grubu hekimleri. Türkiye'de gastroözofageal reflü hastalarında endoskopik bulgular: Çok merkezli prospektif çalışma. Turk J Gastroenterol, 2008; 19(Suppl 1):19-20(SS-25).

11. "El-Serag HB. Time trends of gastroesophageal reflux disease: A systematic review. Clin Gastroenterol Hepatol 2007;5:17-26.

12. Ho KY, Lim LS, Goh WT, Lee JMJ. The prevalence of gastrooesophageal reflux has increased in Asia: a longitudinal study in the community. J Gastroenterol Hepatol 2001;16:A132.

13. Lim SL, Goh WT, Lee JM, et al. Changing prevalence of gastroesophageal reflux with changing time: longitudinal study in an Asian population. J Gastroenterol Hepatol 2005;20:995-1001.

14. Rosaida MS, Goh KL. Opposing time trends in the prevalence of duodenal ulcer and reflux esophagitis in a multiracial Asian population. Gastroenterology 2004;126:A443. 
15. Metz DC, Kroser JA. Helicobacter pylori and gastroesophageal reflux disease. Gastroenterol Clin North Am 1999;28:871-85.

16. Labenz J, Blum AL, Bayerdorffer E, et al. Curing Helicobacter pylori infection in patients with duodenal ulcer may provoke reflux esophagitis. Gastroenterology 1997;112:1442-7.

17. Pohl H, Welch HG. The role of overdiagnosis and reclassification in the marked increase of esophageal adenocarcinoma incidence. J Natl Cancer Inst 2005;97:142-6.
18. Conio M, Cameron AJ, Romero Y, et al. Secular trends in the epidemiology and outcome of Barrett's oesophagus in Olmsted County, Minnesota. Gut 2001;48:304-309.

19. Van Soest EM, Dieleman JP, Siersema PD, et al. Increasing incidence of Barrett's oesophagus in the general population. Gut 2005;54:1062-6.

20. El-Serag HB. Temporal trends in new and recurrent esophageal strictures in the Department of Veterans Affairs. Am J Gastroenterol 2006;101: 1727-33. 